\title{
Toxicity and effect of whitening toothpastes on enamel surface
}

\author{
Sigmar de Mello RODE(a) \\ Tabata do Prado SATO(a) \\ Felipe de Souza MATOS(b) iD \\ Ayla Macyelle de Oliveira \\ CORREIA(c) iD $^{(1)}$ \\ Samira Esteves Afonso \\ CAMARGO(d) \\ (a) Universidade Estadual Paulista - Unesp, \\ Institute of Science and Technology, \\ Department of Dental Materials, São José \\ dos Campos, SP, Brazil. \\ (b) Universidade Federal de Uberlândia - UFU, \\ School of Dentistry, Postgraduate Program \\ in Dentistry, Uberlândia, MG, Brazil. \\ (c) Universidade Estadual Paulista - Unesp, \\ Institute of Science and Technology, \\ Department of Restorative Dentistry, São \\ José dos Campos, SP, Brazil. \\ (d) University of Florida, College of Dentistry, \\ Department of Restorative Dental Sciences, \\ Gainesville, FL, USA.
}

Declaration of Interests: The authors certify that they have no commercial or associative interest that represents a conflict of interest in connection with the manuscript.

\section{Corresponding Author:}

Tabata do Prado Sato

E-mail: tabata.sato@unesp.com

ht1ps://doi.org/10.1590/1807-3107bor-2021.vol35.0025

Submitted: June 9, 2020

Accepted for publication: October 22, 2020

Last revision: November 17, 2020
Abstract: This in vitro study evaluated the biocompatibility and abrasivity of whitening and conventional toothpastes. Samples of conventional (non-whitening) - Edel White Infant (EWI) - and whitening toothpastes - Edel White Whitening (EWW), Edel White CAREFORTE (EWC), Colgate Total $12^{\mathrm{O}}$ Professional (C), and Oral-B Whitening (OB) were dissolved in culture medium $(0.2 \mathrm{~g}$ sample weight per $\mathrm{mL}$ ). Human gingival fibroblasts (hGF) were placed in contact with different dilutions of culture media that had been previously exposed to these toothpastes. Cytotoxicity was then assessed using the methyl tetrazolium test (MTT) and the cell survival rate was determined. Genotoxicity was assessed by the micronucleus test (MNT) and the number of micronuclei was determined before and after exposure to the toothpaste solutions. The enamel surface roughness was evaluated in specimens of bovine teeth ( $n=10$ per group) before and after 10,000 brushing cycles, using the investigated toothpastes. The results were statistically analyzed using the Mann-Whitney $U$ test and two-way ANOVA ( $p<0.05)$. According to the MTT assay, EWW and OB presented significant cytotoxicity $(p<0.01)$, but no genotoxic $(M N T)$ effects $(p>0.05)$. C toothpaste was statistically significantly abrasive to the enamel surface $(p<0.01)$. The findings of this study may be helpful for individualized selection of commercial toothpastes, as some whitening toothpastes present significant cytotoxicity and conventional toothpaste cause significant surface changes.

Keywords: Tooth Wear; Toothpastes; Tooth Bleaching Agents.

\section{Introduction}

Tooth discoloration is considered an essential factor that affects the patient's aesthetic satisfaction. ${ }^{1}$ The desire for whiter teeth has given rise to a new trend, which is greatly influenced by the representation of white and perfect smiles on the media. ${ }^{2}$ Thus, the increasing dissatisfaction of individuals with tooth discoloration has led to the higher consumption of tooth whitening products. ${ }^{3}$

Several different methods of tooth whitening exist, each having its mechanisms of action. The toothpastes correspond to the consumers' expectations. They are more accessible due to the over-the-counter option, which makes them the primary choice for the method of tooth whitening. ${ }^{4}$ 
Usually, a whitening toothpaste does not contain bleach (sodium hypochlorite), but some present low concentrations of carbamide or hydrogen peroxide that help lighten tooth color. Sodium lauryl sulfate (most toxic agent used as detergent), sodium tripolyphosphate, hydrated silica, and aluminum oxide have also been included. ${ }^{5}$ Moreover, contemporary toothpaste includes substantial amounts of sodium monofluorophosphate, silicone dioxide, hydrated silica, sodium benzoate, preservatives, colors, flavors, essences, and buffering agents. ${ }^{6,7}$

During toothbrushing, toothpastes act to reduce biofilm and calculus deposits on teeth and help remove stains and discolorations. ${ }^{5,7,8}$ The removal of these stains could possibly increase toothpaste abrasivity. This may lead to an undesirable increase of tooth surface wear, affecting not only enamel surfaces but also, and more significantly, remineralizable incipient carious and erosive lesions. ${ }^{9,10}$

Studies have shown the effectiveness of whitening agents. However, adverse effects on dental tissues have been reported, which are related to the compounds mentioned before and whose assessment is necessary for them to be considered safe. Thus, it is essential to evaluate the biocompatibility of whitening toothpaste, comparing it with conventional toothpaste. ${ }^{11,12}$

To assess the biocompatibility and the enamel surface, the present study analyzed the cytotoxicity, genotoxicity, and surface roughness of whitening and conventional toothpastes subjected to brushing action.

\section{Methodology}

This project was developed in accordance with the Research Ethics Code (approved under no. 120/2016$\mathrm{PH} / \mathrm{CEP}$ ). Five toothpastes were tested: Edel White Infant (EWI), Edel White Whitening (EWW), Edel White CAREFORTE (EWC), Colgate Total 12 ${ }^{\circ}$ Professional $(\mathrm{C})$, and Oral-B Whitening (OB). The main components of the tested toothpastes are shown in Table 1.

The toothpaste samples were placed in 24-well plates $(0.2 \mathrm{~g}$ per $\mathrm{mL})$ and they were covered with $3 \mathrm{~mL}$ of Dulbecco's Modified Eagle Medium (DMEM) supplemented with $10 \%$ fetal bovine serum, penicillin, and streptomycin, and incubated in the dark for 24 hours at $37^{\circ} \mathrm{C}$. After incubation, these original solutions (1:1) were then serially diluted in cell culture medium and filter sterilized before testing.

Table 1. Main ingredients of the tested toothpastes.

\begin{tabular}{|c|c|}
\hline Toothpastes & Ingredients \\
\hline & Active ingredients: sodium monofluorophosphate 500 ppm F (0.05\% w/fluoride ion). \\
\hline $\begin{array}{l}\text { EWI (Edel White Infant, } \\
\text { Swiss Dental Experts) }\end{array}$ & $\begin{array}{l}\text { Inactive ingredients: water glycerin, calcium carbonate, silica, dicalcium phosphate, xanthan gum, decyl } \\
\text { glucoside, camella sinensis leaf extract, sodium monofluorophosphate, tocopherol, sodium saccharin, sodium } \\
\text { methylparaben, menthol, mentha spicata oil, aroma, menthone, limonene. }\end{array}$ \\
\hline \multirow[b]{2}{*}{$\begin{array}{l}\text { EWW (Edel White } \\
\text { Whitening, Swiss Dental } \\
\text { Experts) }\end{array}$} & Active ingredients: sodium fluoride Max. 1450 ppm F (Ma. 0.145\% w/fluoride ion). \\
\hline & $\begin{array}{l}\text { Inactive ingredients: water, sorbitol, hydrated silica, glycerin, tetrapotassium pyrophosphate, cocamidopropyl } \\
\text { betaine, cellulose gum, aroma, silica, sodium lauroyl sarcosinate, titanium dioxide, sodium fluoride, sodium } \\
\text { methylparaben, sodium saccharin, trisodium phosphate, propyl paraben. RDA: } 80 \text {. }\end{array}$ \\
\hline \multirow[b]{2}{*}{$\begin{array}{l}\text { EWC (Edel White } \\
\text { CAREFORTE, Swiss Dental } \\
\text { Experts) }\end{array}$} & Active ingredients: sodium fluoride Max. 1450 ppm F (Ma. 0.145\% w/fluoride ion). \\
\hline & $\begin{array}{l}\text { Inactive ingredients: water, sorbitol, hydrated silica, glycerin, cocamidopropyl betaine, aroma, xanthan } \\
\text { gum, silica, cellulose gum, calcium lactate, aluminum lactate, sodium bicarbonate, sodium lauroyl sarcosinate, } \\
\text { titanium dioxide, sodium fluoride, tocopheryl acetate, sodium methylparaben, sodium saccharin, bisabolol, } \\
\text { propylparaben, Cl } 16165 \text {. RDA:60. }\end{array}$ \\
\hline $\begin{array}{l}\text { C (Colgate Total } 12^{\circ} \\
\text { Professional, Colgate- } \\
\text { Palmolive Company) }\end{array}$ & $\begin{array}{l}\text { Inactive ingredients: hydrated silica, water, glycerin, sorbitol, sodium lauryl sulfate, copolymer PVM/MA, } \\
\text { flavor, cellulose gum, propylene glycol, sodium hydroxide, carrageenan, sodium fluoride, triclosan, sodium } \\
\text { saccharin, artificial dyes. Cl } 77891 \text {. }\end{array}$ \\
\hline \multirow[b]{2}{*}{$\begin{array}{l}\text { OB (Oral-B Whitening, } \\
\text { Procter \& Gamble) }\end{array}$} & Active ingredients: stannous fluoride $0.454 \%(0.16 \% \mathrm{w} /$ fluoride ion). \\
\hline & $\begin{array}{l}\text { Inactive ingredients: glycerin, hydrated silica, sodium hexametaphosphate, propylene glycol, PEG-6, water, } \\
\text { zinc lactate, trisodium phosphate, flavor, sodium lauryl sulfate, sodium gluconate, carrageenan, sodium } \\
\text { saccharin, polyethylene, xanthan gum, mica, titanium dioxide, blue dyes. }\end{array}$ \\
\hline
\end{tabular}

Source: Camargo SEA, et al. ${ }^{13}$ 


\section{Methyl tetrazolium test (MTT)}

Human gingival fibroblasts (hGF) were routinely cultivated in DMEM supplemented with $10 \%$ fetal bovine serum, penicillin, and streptomycin at $37^{\circ} \mathrm{C}$ and $5 \% \mathrm{CO}_{2}$. The cells were seeded at $8 \times 10^{3}$ cells/well in 96-well plates and incubated for 24 hours at $37^{\circ} \mathrm{C}$. The spectrophotometric readings indicate the level of cellular metabolic activity. Such activity represents the inhibition of succinyl dehydrogenase activity by the contact between the cells and the toothpaste solutions. The cells were exposed to $200 \mu \mathrm{L}$ of the original solutions (1:1) and serially diluted to 1:2, 1:4, 1:8, 1:16, and 1:32. After 2 minutes of stimulation (the recommended and the applied average toothbrushing time), ${ }^{14,15}$ the cells were washed with phosphate-buffered saline (PBS) to neutralize the further effects of the toothpastes on the cells. Cell survival rate was determined by using the MTT assay (Sigma-Aldrich, St Louis, USA). A volume of $100 \mu \mathrm{L}$ of MTT solution was added to each well and the cells were incubated for 2 hours. The resulting formazan crystals were dissolved by removing the culture medium and adding $100 \mu \mathrm{L}$ of dimethyl sulfoxide solvent (Sigma-Aldrich) to each well. The plates were shaken at room temperature for 10 minutes to dissolve the crystals and were then analyzed using a microplate reader. Enzyme inhibition was quantified using a spectrophotometer (Asys Hitech $\mathrm{GmbH}$, Eugendorf, Austria) at $570 \mathrm{~nm}$. Four replicate cell cultures were exposed to each of the serial dilutions of the solutions in three independent experiments. The absorbance readings were normalized in untreated control cultures $(=100 \%)$ and the differences between the median values were statistically analyzed by the Mann-Whitney U test for comparison among groups and the two-way-ANOVA post-test at a significance level of 5\% (Graphpad Prism, version 6.0; La Jolla, USA).

\section{Micronucleus test (MNT)}

Human gingival fibroblasts (hGF) were routinely cultivated in DMEM supplemented with $10 \%$ fetal bovine serum, penicillin, and streptomycin at $37^{\circ} \mathrm{C}$ and $5 \% \mathrm{CO}_{2}$. The cells were grown at a density of $2 \times 10^{4}$ in 24-well plates and incubated for 24 hours at $37^{\circ} \mathrm{C}$ and $5 \% \mathrm{CO}_{2}$. The cell cultures were then exposed to different dilutions (1:1, 1:2, 1:4, and 1:8) of the toothpaste solutions for 24 hours and fixed in $4 \%$ formaldehyde thereafter. Then, Fluoroshield with DAPI (Sigma-Aldrich) and phosphate-buffered saline (PBS, Cultilab, Campinas, SP, Brazil) were added to the wells, which were photographed with a digital camera (Sony F828 Digital, CyberShot, 8.0 megapixels) coupled to an inverted light microscope (Carl Zeiss Microscope Micro lmaging GmbH - Axiovert 40C, Germany). At least 10 photos in different fields were taken in each well. A cell counter (Image J software) was used to help with the count of micronuclei. The number of micronuclei was determined microscopically in 2,000 cells/well and the differences between the median values were statistically analyzed using the Mann-Whitney U test and two-way-ANOVA at a 5\% significance level.

\section{Analysis of enamel surface roughness}

A total of 50 bovine tooth specimens were used and assigned to five groups $(n=10)$. The specimens were removed from the vestibular and lingual surfaces of the tooth crown containing enamel and dentin, cut into a cylindrical shape measuring $3 \mathrm{~mm} \times 3 \mathrm{~mm}$, by means of a Micro Mill (SIEG, Shangai, China) cutter, and were embedded in chemically activated acrylic resin blocks.

The blocks were polished with 120-, 300-, and 600-grit water abrasive papers on a polishing machine (Polipan 2 Pantec, São Bernardo do Campo, Brazil). After that, enamel surface roughness was measured with a Model FM 700 rugosimeter (Future Tech, Shinagawa-ku, Japan) before the brushing cycles.

A MEV-2 (Odeme, Luzerna, Brazil) brushing machine was used, with Edel white (Soft Flosserbrush, Edel+white, Switzerland) 39 toothbrush heads coupled to the machine. Brushing was performed simultaneously in all groups using the solutions prepared with the following toothpastes: Edel White Infant (EWI), Edel White Whitening (EWW), Edel White CAREFORTE (EWC), Colgate Total $12^{\circ}$ Professional (C), and Oral-B Whitening (OB). The solutions contained 6 grams $(\approx 4.6 \mathrm{~mL})$ of toothpaste and $6 \mathrm{~mL}$ of distilled water adjusted in the ratio of $1: 1{ }^{11}$ Four $10-\mathrm{mm}$ syringes with the toothpaste solutions to be injected during the process were 
coupled to the brushing equipment. The samples were subjected to brushing for 20 minutes, totaling 10,000 cycles, which correspond to one year of tooth brushing. ${ }^{11}$

After the brushing procedure, surface roughness was measured again on all samples and the mean results of three measurements were considered.

\section{Results}

\section{MTT}

Cell proliferation was significantly different between the experimental groups and the untreated control group for all dilutions $(\mathrm{p}<0.0001)$, except for EWI (1:8 dilution) $(\mathrm{p}=0.5836)$.

EWI was the least cytotoxic toothpaste, showing cell viability rates greater than $50 \%$ for all dilutions. The EWI original solution (1:1) presented statistical significance compared with EWW, C, and OB $(\mathrm{p}<0.001)$.

EWC resulted in cell viability rates lower than $44 \%$ for 1:1 and 1:2 dilutions, with statistical significance compared with EWI, EWW, C, and OB ( $p<0.05)$.

EWW was considered the most toxic toothpaste tested in this experiment, since the difference in survival rates between EWW and all other materials was statistically significant for all dilutions $(p<0.01)$.

Colgate yielded cell viability rates lower than $18 \%$ for 1:1 to 1:8 dilutions (Figure 1), presenting statistical significance compared with the untreated control $(p<0.05)$. The original solutions (1:1) of Colgate reduced the survival rates of fibroblasts to $6.68 \%$, which was significant in relation to the untreated control $(p<0.05)$. Solutions of Colgate were significantly more toxic to gingival fibroblasts than solutions of EWI and EWC for both original solutions and all dilutions $(\mathrm{p}<0.001)$.

Oral B Whitening (OB) yielded cell viability rates lower than $9 \%$ for both original solutions and their dilutions up to 1:16 (Figure 1), presenting statistical significance compared with the untreated control $(\mathrm{p}<0.05)$.

Summarizing the results for the MTT, the toxicity of the tested toothpastes can be ranked in the following order from the most toxic to the least toxic: EWW $>$ OB $>$ C $>$ EWC $>$ EWI.

\section{MNT}

Micronucleus formation was analyzed in gingival fibroblasts exposed to the toothpaste solutions. Ethyl methanesulfonate (EMS), which was used as a positive control, increased the number of micronuclei in the treated cultures by approximately 6 -fold compared with that detected in the untreated control.

All toothpastes tested in this study increased the number of micronuclei similarly to the untreated control, presenting statistical significance $(p<0.05)$ compared with EMS (Figure 2).

Higher concentrations of the toothpastes caused cytotoxicity in gingival fibroblasts, and micronuclei could not be counted.

\section{Enamel surface roughness}

Table 2 shows the initial and final mean values of enamel surface roughness and the difference between them.

Colgate $(\mathrm{C})$ showed a higher enamel surface roughness in comparison with the other toothpastes $(\mathrm{p}<0.005)$. Positive values (F- I) of EWI, EWC, and C indicate an increase in surface roughness, and negative values (F- I) of EWW and OB represent a decrease.

\section{Discussion}

In the present study, we evaluated the cytotoxicity and genotoxicity of whitening and conventional toothpastes and their effect on the enamel roughness of permanent teeth.

Cell viability was assessed by the MTT assay, which serves as an indicator of mitochondrial activity and, therefore, all toothpastes presented some degree of toxicity - significantly higher for EWW in comparison with the other groups ( $p<0.01)$. These results are consistent with those of another study that revealed time-dependent cytotoxic effects on viable cells for 16 different types of commercial toothpastes. ${ }^{16}$

Several toothpaste compounds may have a toxic effect, such as sodium lauryl sulfate, sodium monofluorophosphate, hydrated silica, sodium benzoate, silicone dioxide, colors, flavors, preservatives, and different essences. Besides, our results suggest that the cytotoxic behavior of 
Edel white infant

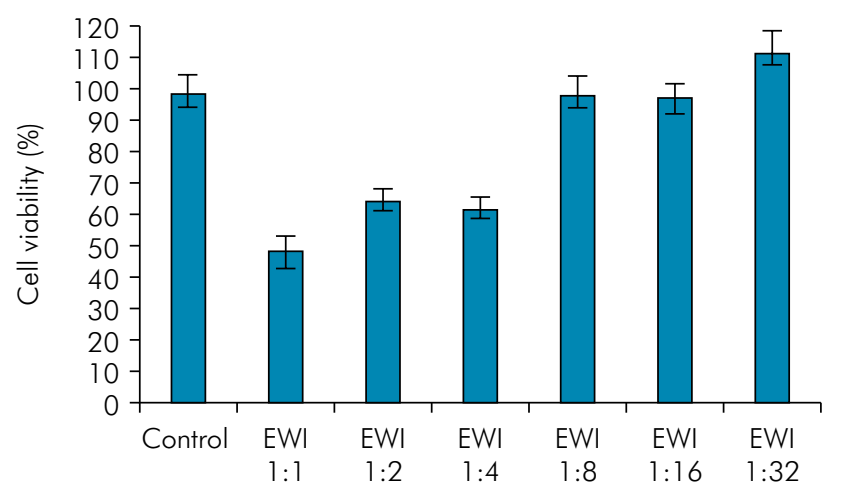

Edel white CAREFORTE

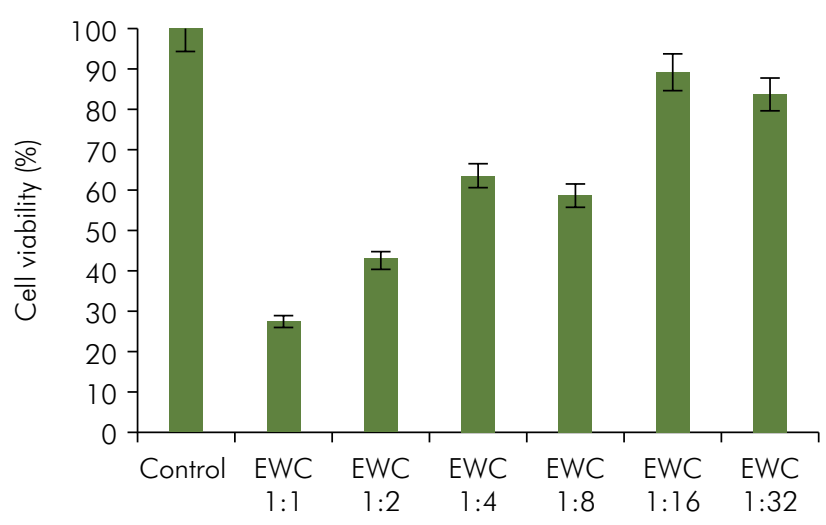

Edel white whitening

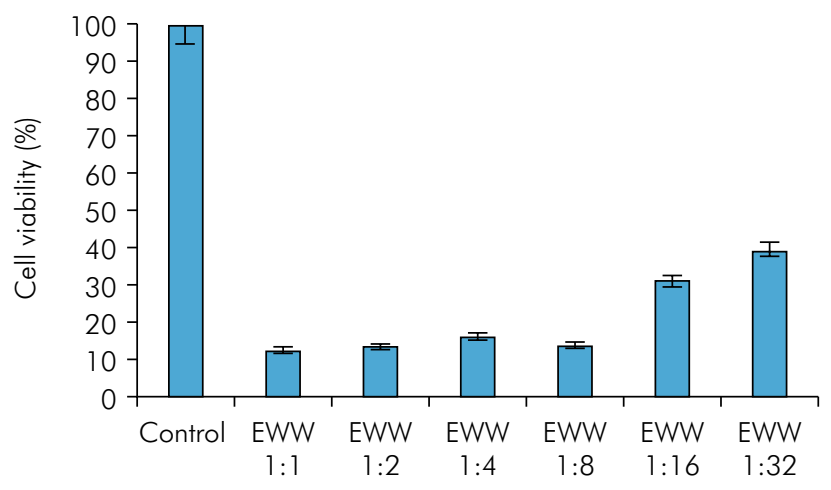

Colgate

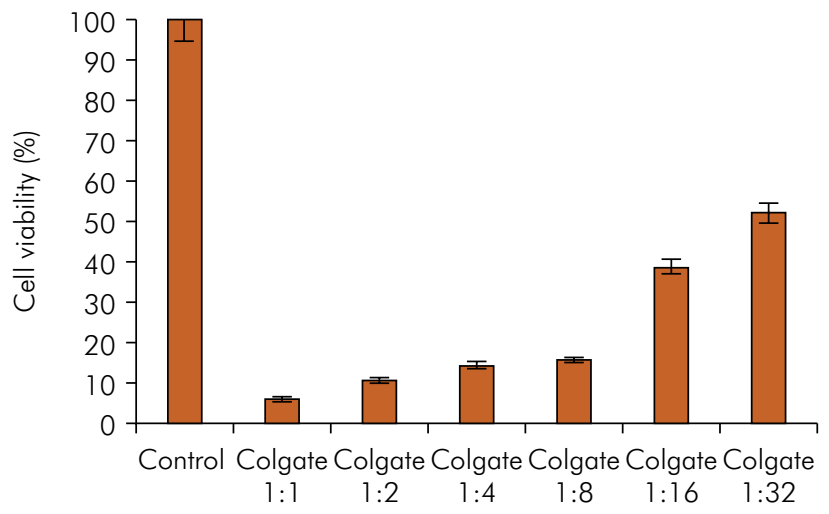

Oral B

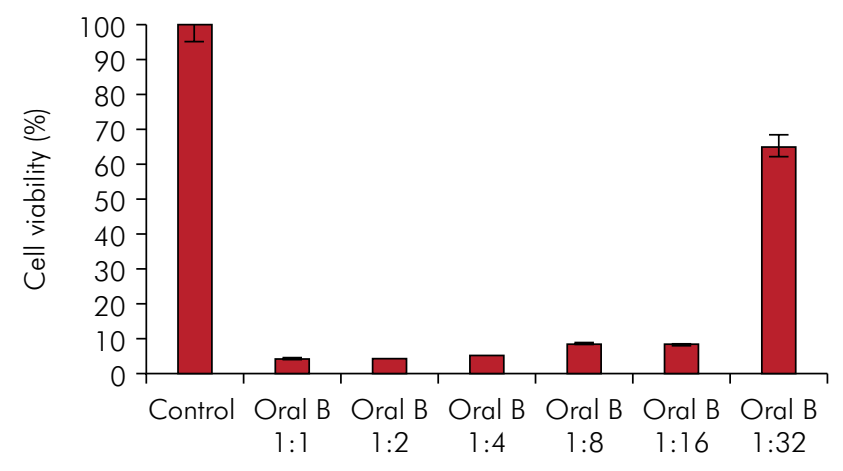

Figure 1. Cytotoxicity of toothpastes in hGF after exposure to solutions. Original solutions (1:1) were serially diluted with cell culture medium as indicated. Bars represent medians plus 25th and 75th percentiles. Statistically significant differences between untreated and treated cell cultures are indicated by asterisks.

toothpastes might be due to fluoride, which can induce oxidative stress, decrease intracellular homeostasis and lipid peroxidation, altering gene expression and, consequently, apoptosis. ${ }^{17}$
Sodium lauryl sulfate, a detergent that is also present in the toothpastes tested in this study, showed significant soft tissue damage in vitro ${ }^{16,18}$ and oral mucosa irritation in vivo.,19 However, not 


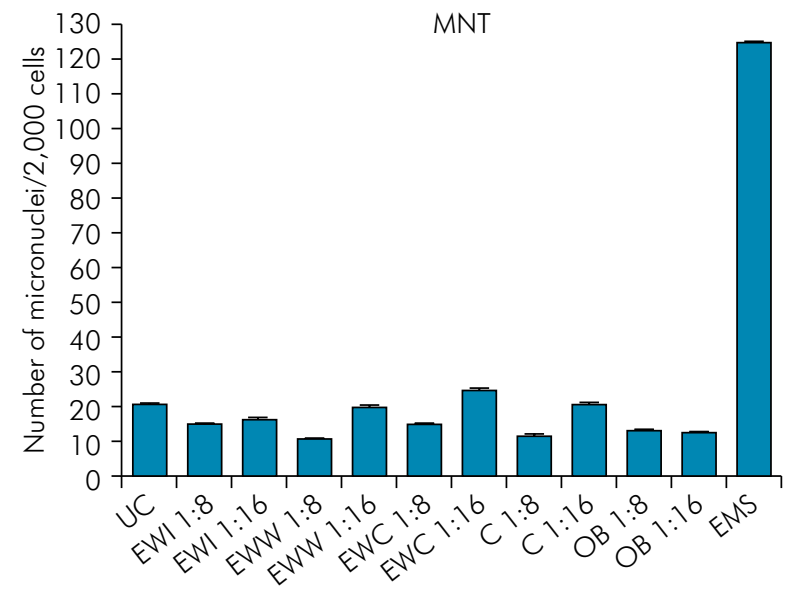

Figure 2. Induction of micronuclei in gingival fibroblasts after exposure to toothpastes. The micronuclei induced by the toothpastes were obtained from five treated cell cultures, and bars represent medians (25th and 75th percentiles).

all toothpastes contain sodium lauryl sulfate, even those with significant cytotoxicity.

In this study, we used EMS as a positive control due to its high genotoxic potential and ability to stimulate micronucleus formation. ${ }^{20,21}$ Several dilutions of the tested toothpastes (1:8 and 1:16) were chosen according to the results of a preliminary study. ${ }^{11}$ Toothpastes induced micronucleus formation similar to the untreated control. Also, all toothpastes caused the formation of lower numbers of micronuclei than did the positive control (EMS).

The main component of toothpastes responsible for mechanical removal is the abrasive agent, used for cleaning teeth. ${ }^{7,11,22,23,24}$ In this way, the frequent use of abrasive toothpastes could also be associated with dental enamel and oral cell damage, ${ }^{11}$ and this study showed that Colgate promoted the highest alteration of enamel surface roughness ( $p<0.005)$. Moreover, this abrasive agent can cause other undesirable effects such as association with fluoride, which reduces its ionic form, interfering in the remineralization process. ${ }^{25,26}$

Therefore, the properties of toothpastes should be well known before they are recommended to patients. Even though our findings suggest all tested toothpastes showed no genotoxic effects, Edel White Whitening and Oral-B Whitening presented significant cytotoxicity. Also, Colgate promoted a higher alteration of enamel surface roughness, which may cause undesirable reactions in patients.

\section{Conclusion}

Despite the limitations of the present study, its findings may be helpful for individualized selection of commercial toothpastes. Some whitening toothpastes present significant cytotoxicity, whereas conventional toothpastes promote significant enamel surface changes. Additional in vivo studies are needed to determine the interaction of other factors such as in vivo mechanisms that may minimize the harmful effects.

\section{Acknowledgements}

The authors would like to thank the São Paulo Research Foundation (FAPESP) for the financial support and Andresa Graciutti Botan and Renata Pilli Jóias for their methodological support. The authors would like to acknowledge Edel White for the support.

Table 2. Mean values of enamel surface roughness $(\mu \mathrm{m})$ and standard deviations from the initial to final values.

\begin{tabular}{|c|c|c|c|c|}
\hline \multirow{2}{*}{ Toothpastes } & Initial (I) & Final (F) & \multirow{2}{*}{$(F-I)$} & \multirow{2}{*}{$\mathrm{p}$-value } \\
\hline & Mean $(\mathrm{mm}) \pm \mathrm{SD}$ & Mean $(\mathrm{mm}) \pm \mathrm{SD}$ & & \\
\hline EWI & $0.119 \pm 0.01$ & $0.141 \pm 0.017$ & $0.022 \pm 0.02$ & 0.2816 \\
\hline EWW & $0.272 \pm 0.021$ & $0.269 \pm 0.027$ & $-0.003 \pm 0.034$ & 0.1570 \\
\hline EWC & $0.176 \pm 0.022$ & $0.204 \pm 0.025$ & $0.027 \pm 0.033$ & 0.4198 \\
\hline C & $0.243 \pm 0.067$ & $0.75 \pm 0.218$ & $0.507 \pm 0.228$ & 0.0328 \\
\hline $\mathrm{OB}$ & $0.186 \pm 0.027$ & $0.147 \pm 0.007$ & $-0.039 \pm 0.028$ & 0.1800 \\
\hline
\end{tabular}

*Statistically significant difference. 


\section{References}

1. Oliveira J, Sarlo RS, Bresciani E, Caneppele T. Whitening efficacy of whitening mouth rinses used alone or in conjunction with carbamide peroxide home whitening. Oper Dent. 2017 May/Jun;42(3):319-26. https://doi.org/10.2341/15-361-L

2. Carey CM. Toot whitening: what we now know. J Evid Based Dent Pract. 2014;14 Suppl:70-76. https://doi.org/10.1016/i.jebdp.2014.02.006

3. Trakiniene G, Daukontiene S, Jurenas V, Svalkauskiene V, Smailiene D, Lopatiene K, et al. The effect of the teeth bleaching with $35 \%$ hydrogen peroxide on the tensile bond strength of metal brackets. Sci Rep. 2017 Apr;7(1):798. https://doi.org/10.1038/s41598-017-00843-z

4. Pintado-Palomino K, Vasconcelos CV, Silva RJ, Fressatti AL, Motta BJ, Pires-DE-Souza FC, et al. Effect of whitening dentifrices: a double-blind randomized controlled trial. Braz Oral Res. 2016 Oct;30(1):e82. https://doi.org/10.1590/1807-3107BOR-2016.vol30.0082

5. Meyers IA, McQueen MJ, Harbrow D, Seymour GJ. The surface effect of dentifrices. Aust Dent J. 2000 Jun;45(2):118-24. https://doi.org/10.1111/j.1834-7819.2000.tb00251.x

6. Joiner A. Whitening toothpastes: a review of the literature. J Dent. 2010;38 Suppl 2:e17-24. https://doi.org/10.1016/i.jdent.2010.05.017

7. Cvikl B, Lussi A, Gruber R. The in vitro impact of toothpaste extracts on cell viability. Eur J Oral Sci. 2015 Jun;123(3):179-85. https://doi.org/10.1111/eos.12177

8. Lima DA, Silva AL, Aguiar FH, Liporoni PC, Munin E, Ambrosano GM, et al. In vitro assessment of the effectiveness of whitening dentifrices for the removal of extrinsic tooth stains. Braz Oral Res. 2008 Apr-Jun;22(2):106-11. https://doi.org/10.1590/S1806-83242008000200003

9. Pontefract H, Courtney M, Smith S, Newcombe RG, Addy M. Development of methods to enhance extrinsic tooth discoloration for comparison of toothpastes. 1. Studies in vitro. J Clin Periodontol. 2004 Jan;31(1):1-6. https://doi.org/10.1111/j.0303-6979.2004.00423.x

10. Alshara S, Lippert F, Eckert GJ, Hara AT. Effectiveness and mode of action of whitening dentifrices on enamel extrinsic stains. Clin Oral Investig. 2014;18(2):563-9. https://doi.org/10.1007/s00784-013-0981-8

11. Camargo SE, Jóias RP, Santana-Melo GF, Ferreira LT, El Achkar VN, Rode SM. Conventional and whitening toothpastes: cytotoxicity, genotoxicity and effect on the enamel surface. Am J Dent. 2014 Dec;27(6):307-11.

12. Borges AB, Santos LF, Augusto MG, Bonfiette D, Hara AT, Torres CR. Toothbrushing abrasion susceptibility of enamel and dentin bleached with calcium-supplemented hydrogen peroxide gel. J Dent. 2016 Jun;49:54-9. https://doi.org/10.1016/i.jdent.2016.03.009

13. Camargo SE, Jóias RP, Santana-Melo GF, Ferreira LT, El Achkar VN, Rode SM. Conventional and whitening toothpastes: cytotoxicity, genotoxicity and effect on the enamel surface. Am J Dent. 2014 Dec;27(6):307-11.

14. Creeth JE, Gallagher A, Sowinski J, Bowman J, Barrett K, Lowe S, et al. The effect of brushing time and dentifrice on dental plaque removal in vivo. J Dent Hyg. 2009;83(3):111-6.

15. Winterfeld T, Schlueter N, Harnacke D, Illig J, Margraf-Stiksrud J, Deinzer R, et al. Toothbrushing and flossing behaviour in young adults: a video observation. Clin Oral Investig. 2015 May;19(4):851-8. https://doi.org/10.1007/s00784-014-1306-2

16. Ghapanchi J, Kamali F, Moattari A, Poorshahidi S, Shahin E, Rezazadeh F, et al. In vitro comparison of cytotoxic and antibacterial effects of 16 commercial toothpastes. J Int Oral Health. 2015 Mar;7(3):39-43.

17. Barbier O, Arreola-Mendoza L, Del Razo LM. Molecular mechanisms of fluoride toxicity. Chem Biol Interact. 2010 Nov;188(2):319-33. https://doi.org/10.1016/i.cbi.2010.07.011

18. Moore C, Addy M, Moran J. Toothpaste detergents: a potential source of oral soft tissue damage? Int J Dent Hyg. 2008 Aug;6(3):193-8. https://doi.org/10.1111/j.1601-5037.2008.00307.x

19. Rantanen I, Jutila K, Nicander I, Tenovuo J, Söderling E. The effects of two sodium lauryl sulphate-containing toothpastes with and without betaine on human oral mucosa in vivo. Swed Dent J. 2003;27(1):31-4.

20. Schweikl H, Schmalz G. The induction of micronuclei in V79 cells by the root canal filling material AH plus. Biomaterials. 2000 May;21(9):939-44. https://doi.org/10.1016/S0142-9612(99)00267-7

21. Camargo SE, Camargo CH, Hiller KA, Rode SM, Schweikl H, Schmalz G. Cytotoxicity and genotoxicity of pulp capping materials in two cell lines. Int Endod J. 2009 Mar;42(3):227-37. https://doi.org/10.1111/i.1365-2591.2008.01506.x

22. Pontefract H, Courtney M, Smith S, Newcombe RG, Addy M. Development of methods to enhance extrinsic tooth discoloration for comparison of toothpastes. 2. Two-product clinical study. J Clin Periodontol. 2004 Jan;31(1):7-11. https://doi.org/10.1111/i.0303-6979.2004.00422.x

23. Demarco FF, Meireles SS, Masotti AS. Over-the-counter whitening agents: a concise review. Braz Oral Res. 2009;23 Suppl 1:64-70. https://doi.org/10.1590/S1806-83242009000500010

24. Özkan P, Kansu G, Özak ST, Kurtulmuş-Yilmaz S, Kansu P. Effect of bleaching agents and whitening dentifrices on the surface roughness of human teeth enamel. Acta Odontol Scand. 2013 May-Jul;71(3-4):488-97. https://doi.org/10.3109/00016357.2012.696691

25. Altenburger MJ, Bernhart J, Schicha TD, Wrbas KT, Hellwig E. Comparison of in vitro fluoride uptake from whitening toothpastes and a conventional toothpaste in demineralised enamel. Schweiz Monatsschr Zahnmed. 2010;120(2):104-13.

26. Magalhães AC, Kato MT, Rios D, Wiegand A, Attin T, Buzalaf MA. The effect of an experimental $4 \%$ Tif4 varnish compared to NaF varnishes and 4\% TiF4 solution on dental erosion in vitro. Caries Res. 2008;42(4):269-74. https://doi.org/10.1159/000135672 